\title{
Soft tissue management: the key to the success of periodontal treatment
}

\author{
A. Popelut \\ 1 Hospital University Assistant Lecturer in Periodontology, Bordeaux \\ 2 Exclusive private practice in periodontology and implantology, Bordeaux
}

\begin{abstract}
Esthetic demands are consistently on the rise, the treatment of gingival recession through periodontal plastic surgery has become an important treatment in our repertoire. The etiology of recession is well defined: brushing-related trauma and bacterial plaque are the most frequent etiological factors for gingival recession, and they act on bony dehiscence that may be anatomical or acquired. The objectives of these procedures are to increase the width of the keratinized tissues and the volume of the soft tissues. The evolution of orthodontics with the incorporation of microsurgical techniques, which are minimally invasive and do not require incisions, has led to more predictable esthetic results. The tunnel technique thus perfectly fulfills these criteria for success and ease of recovery with no scarring, and the natural appearance of the epithelial transitions.
\end{abstract}

\section{KEYWORDS}

Gingival recession, root coverage, periodontal plastic surgery, tunnel technique, soft tissue augmentation

\section{INTRODUCTION}

Periodontal surgery with the use of gingival grafts has evolved dramatically over the past 50 years with two major objectives: to increase the width of keratinized tissues and increase the volume of soft tissues. Initially, surgical interventions were based on the belief that a minimum width of keratinized gingiva would be required to maintain the good health and stability of periodontal tissues $^{12}$. As a result, root canal filling techniques and apically repositioned flaps have been recommended to increase keratinized

\section{Address for correspondence:}

Antoine Popelut, 
gingival width. Then the use of free epithelialized grafts was proposed instead, thanks to the work of Karring et al. ${ }^{7}$ on the genetic determination of periodontal tissues.

Progressively, epithelial-connective graft surgery to increase the width of the gingiva decreased when it became clear that the importance of the size of keratinized tissue had been overestimated in the past. Periodontists then began to use free gingival grafts for esthetic corrections such as soft tissue recession coverage ${ }^{3}$, soft tissue augmentation of the ridges, and alveolar preservation in esthetic areas. Moreover, the evolution of the procedures for increasing soft tissues has been marked by a perpetual increase in the esthetic demands of our patients. However, the epithelial graft has limitations on qualitative results (esthetic integration, surface, color, scarring) for the reconstruction of soft tissues for esthetic indications.

The search for better alternatives has allowed us to develop the techniques of grafting the subepithelial connective tissue $^{8}$ which has a predictable esthetic result. Thus, the evolution of soft tissue autografts from the epithelial-connective tissue graft to the subepithelial connective tissue graft has represented a change in philosophy that is theoretically grounded in the literature by the transition from classical mucogingival surgery to periodontal plastic surgery. In 1993, Miller introduced the term "periodontal plastic surgery," accepted by the international scientific community in 1996, which was defined as "surgery performed to prevent or correct defects of the gingiva, alveolar mucosa, or bone, that are caused via a traumatic, inflammatory, or anatomical manner." Today, soft tissue augmentation is indicated for the treatment of soft tissue recession at the level of the teeth ${ }^{17}$, for immediate implant prostheses or fixed partial dentures, and for the reconstruction of the dental papilla.

In addition, it may also be recommended to thicken soft tissues especially before orthodontic $^{16}$ or preservative treatment and to mask discolored roots and implant components.

Given the challenges of soft tissue increase procedures in periodontal and implant plastic surgery, the free gingival graft has therefore disappeared from the esthetic domain and its scope has been limited to the increase in keratinized tissues around teeth and implants in areas without esthetic importance. Thus, this article will only discuss the esthetic aspects of surgery using tunnel techniques to obtain the main criteria for a successful recovery: the absence of scarring and the natural appearance of the epithelial transitions.

\section{ETIOPATHOGENESIS}

The marginal gingiva is clinically represented by a scalloped line that follows the contour of the enamel-cement junction, 1-2 $\mathrm{mm}$ from the crown. The gingival recession is an apical displacement of the marginal gingiva with the exposure of the root surface to the oral cavity. A bone dehiscence must be present so that the gingival recession can be seen ${ }^{9}$. Bone dehiscence can be a 


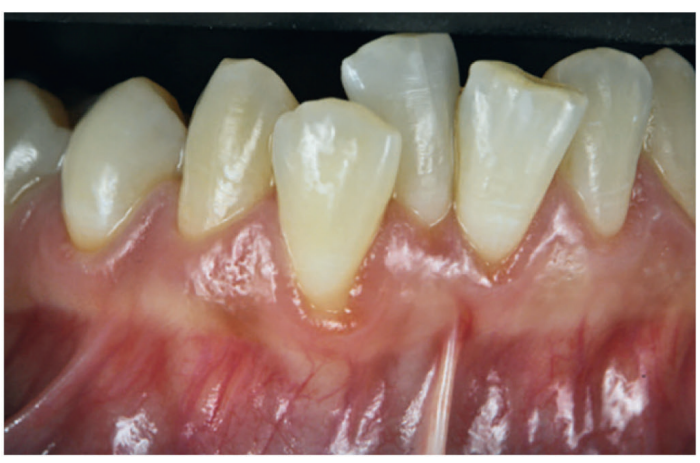

a

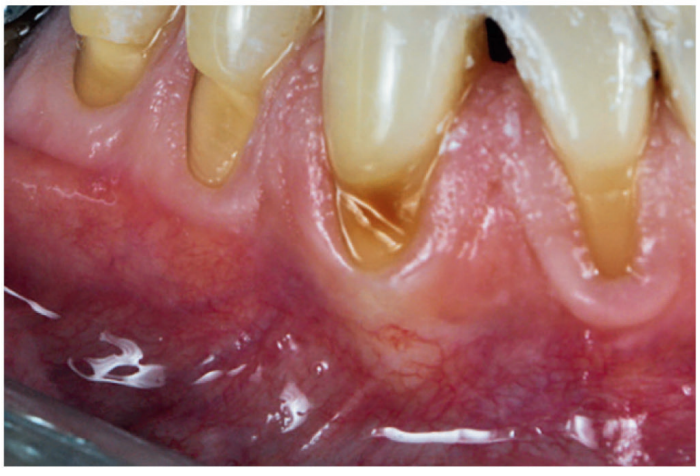

C

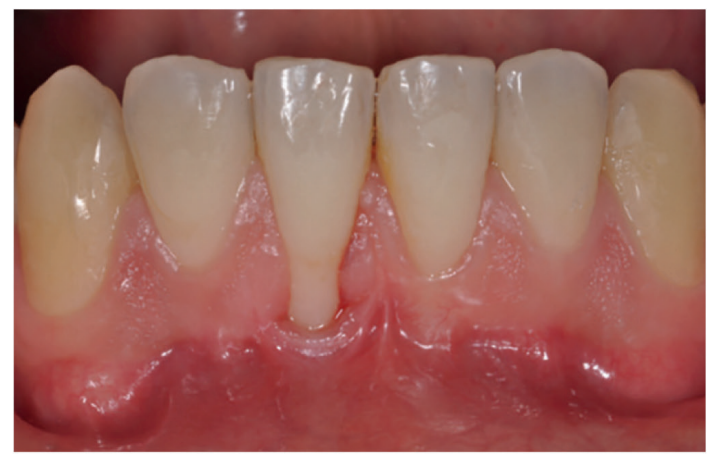

b

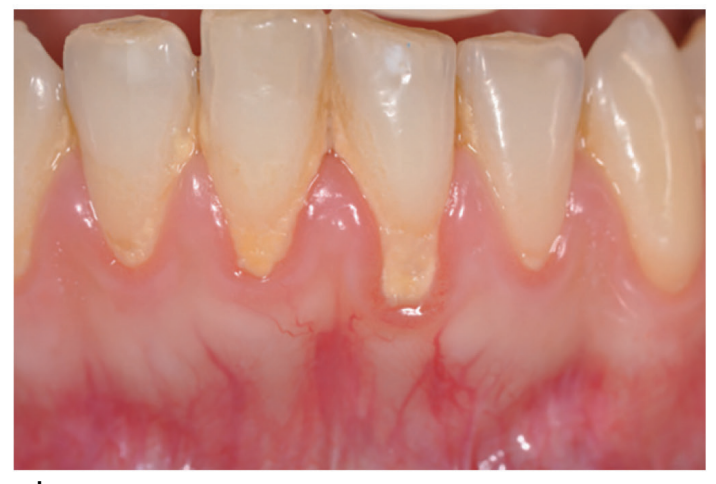

d

Figure 1

For a gingival recession to appear, there must be dehiscence either (a) related to tooth position or (b) orthodontic treatment. The origin of the recession can be the consequence (c) of a trauma caused by brushing, (d) of poor plaque control.

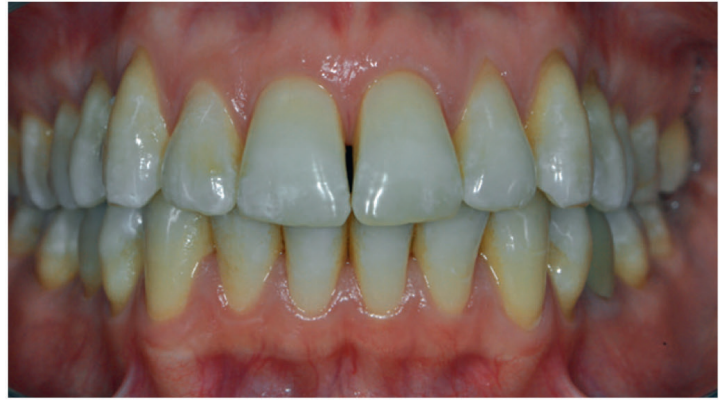

a

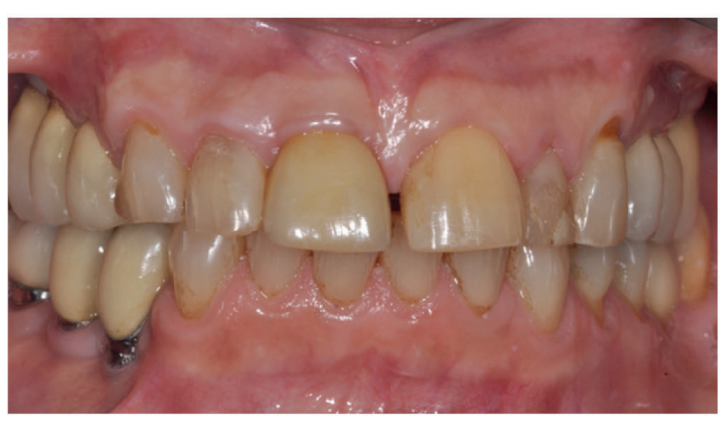

b

Figure 2

(a) patient with a fine periodontal biotype. (b) Patient with a thick periodontal biotype. 
consequence of bone anatomy or associated with tooth position, an inflammatory process (periodontitis, lack of biological space), an occlusal overload, or an orthodontic movement (fig. 1a and b). The main factors behind gingival recessions following bone dehiscence are trauma caused by brushing (fig. 1c) and poor plaque control (fig. 1d).

Other triggers are induced (oral habits), iatrogenic, and/or the presence of subgingival restorations. In addition, gingival recession may be due to orthodontic treatment at sites with bone dehiscence or when orthodontic treatment causes the tooth to move outside its bony envelope ${ }^{6}$ Three major factors are associated with increased susceptibility to gingival recession: thin gingival tissue, progression of gingival reces- sion, and positive history of inflammatory periodontal disease.

Gingival tissue shows varying clinical appearance-thick, medium, or fine. The fine biotype (Fig. 2a) is characterized by a relatively thin and marked gingival tissue, a thin band of keratinized gum, and a scalloped bone and gingival architecture ${ }^{13,14}$. The thick biotype (Fig. 2b) is characterized by thick, dense, fibrous tissue, a wide gum band and a flat gingival architecture 13,14. So individuals with a fine gingival biotype have a greater risk of gingival recession than those with a thick biotype. On the other hand, patients with a thick biotype are more prone to the risk of inflammation and the formation of periodontal pockets during periodontal disease.

\section{CLASSIFICATION, DIAGNOSIS, AND PROGNOSIS OF RECESSIONS}

Gingival recession can be treated with different surgical procedures and the root coverage can be obtained regardless of the surgical approach taken. The most important risk factor for the recovery of the recession after surgery is the height of the interdental periodontal support (clinical attachment and alveolar bone levels). In the case of a tooth with a healthy periodontium, the papillae completely fill the interdental spaces, and there is no loss of clinical attachment or bone loss. Periodontal examinations and retro-alveolar radiography confirm this healthy condition. Gingival recessions were classified by Miller ${ }^{1}$ (Fig. 3) into four classes according to the prognosis of root recovery. In class-I and class-Il gingival recessions, there is no interproximal bone loss, and the mesial and distal papillae are intact.

The difference between the two classes is because of the height of the root exposure, which reaches the mucogingival junction in class-II cases, and does not reach in class-I cases. Full root coverage is possible and predictable. In class-III gingival recessions, the mesial and distal papillae are moderately diminished, and a partial recovery of the root can be accomplished. In addition, dental malposition limits the possible amount of root coverage. In class-IV gingival recessions, the mesial and distal papillae have completely disappeared. The loss of interproximal periodontal attachment is so severe that the results are unpredictable. This classification is currently actively discussed 


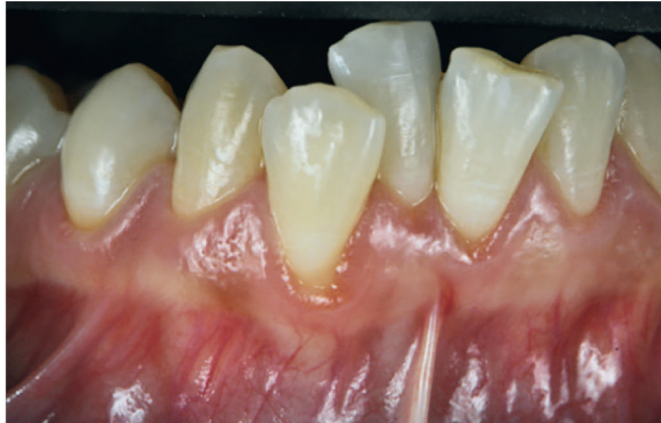

a

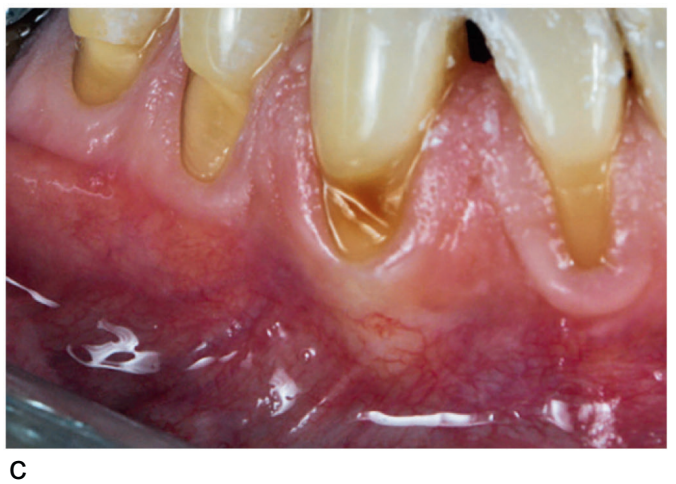

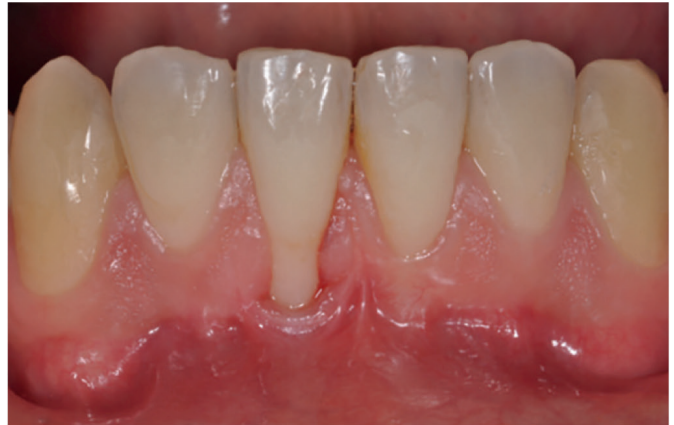

b

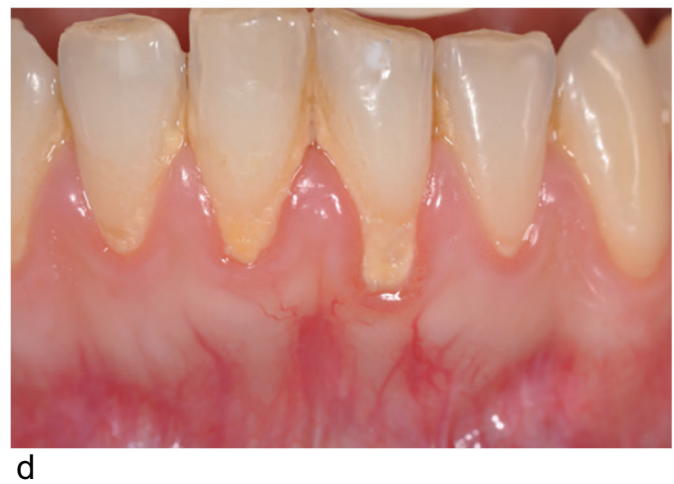

Figure 3

Miller Classification of marginal tissue recessions. The root coverage is predictable for class-I (a) (b) recessions. Partial recoverage may be expected in the treatment of class-III (c) recessions. The results are unpredictable for class-IV (d) recessions.

because of discrepancies between prognoses and the results reported in the literature.

For example, Cairo et al. ${ }^{4}$ have recently introduced a new system for classifying gingival recessions using the interproximal clinical attachment level as a criterion for identification. Three types of recession (RT) have been identified. The RT1 class defines a gingival recession with no loss of interproximal attachment. The RT2 class is a recession with an interproximal loss of attachment less than or equal to the most apical level of the vestibular recession. The RT3 class has a prox- imal cross-binding loss exceeding the apical limit of the vestibular recession. The results of this study show that the type of recession is a powerful indicator of the expected result after different surgeries. The full recovery prognostic value decreases from the RT1 class down to the RT3 class.

The prognosis of success is one of the main criteria when deciding to operate.

The results of treatment are thus a function of the determined objective. Several factors are to be considered: the type of defect, the patient, the technique used, and the experience of the operating surgeon. 


\section{INDICATIONS OF TREATMENTS}

The question of whether surgical intervention is required must be answered precisely. The decision to treat is most often based on esthetic considerations; however, there is a medical indication for treatment in case the gingival recession progresses, and where the site of recession is likely to result in an injury that is difficult to clean. Therefore, Merijohn ${ }^{10}$ defines specific patient selection criteria:

- documented evidence of progressive gingival recession;

- persistent gingival inflammation despite appropriate therapeutic interventions in combination with $5-\mathrm{mm}$ clinical attachment loss and/or gingival recession of $\geq 2 \mathrm{~mm}$;

- a gingival recession with persistent gingival inflammation despite appropriate therapeutic interventions, associated with a shallow vestibule that restricts access to effective oral hygiene, and a poor position that compromises effective oral hygiene;

- the tooth with a gingival recession requires a subgingival restoration, an orthodontic treatment based on the associated movement or a support to stabilize a removable device.

Regarding orthodontic treatment, the risk of gingival recession is a function of the extent and direction of motion, the force applied, the presence of gingival inflammation, and the biotype of tissues surrounding the tooth. It is therefore imperative to evaluate the biotype of periodontal tissues before orthodontic treatment, especially if the applied movement is in the vestibular direction. If the orthodontic movement of the tooth occurs in the bony envelope, the risk of recession is low regardless of the biotype. If, on the other hand, the movement applied to the tooth level is likely to cause dehiscence, the risk of root stripping depends on the thickness of the periodontal tissues surrounding the teeth. A fine biotype is associated with a higher risk of recession, especially because the orthodontic movement will decrease the thickness of the tissues (fig. 4).

In the presence of fine biotype or a tooth with bone dehiscence, a gingival augmentation should be considered to avoid a gingival recession or
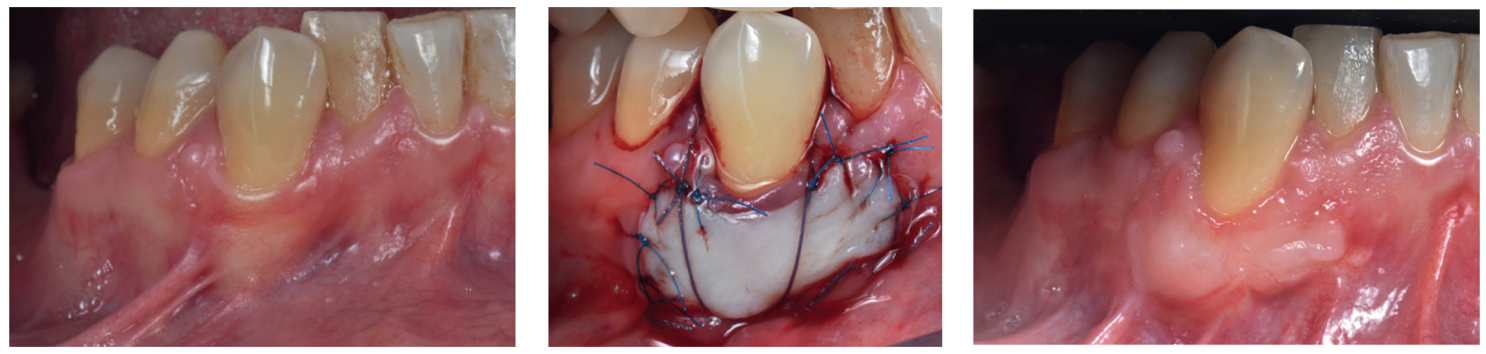

Figure 4

A epithelial-connective tissue graft was performed before orthodontic treatment. This treatment is recommended due to the absence of keratinized tissue associated with an initial movement caused by vestibular orthodontic movement. 


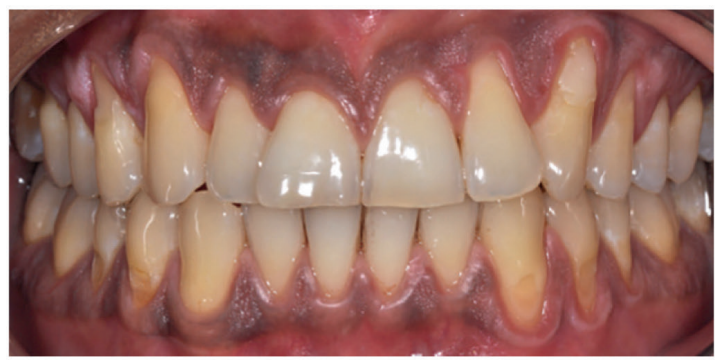

a

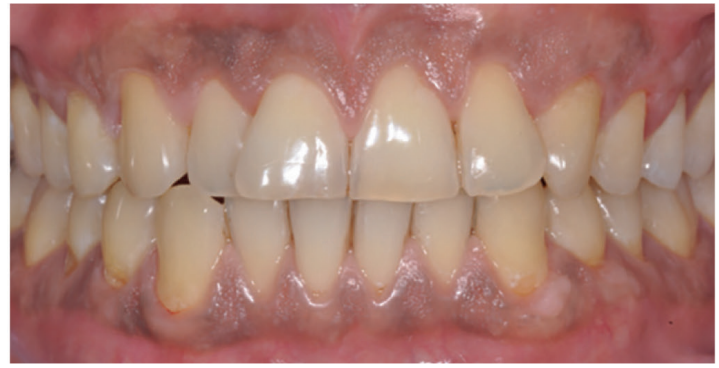

C

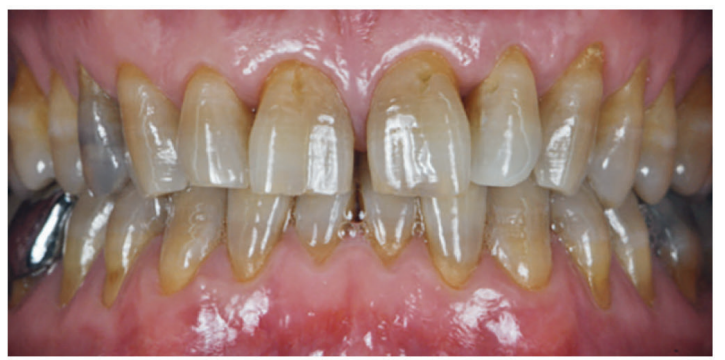

b

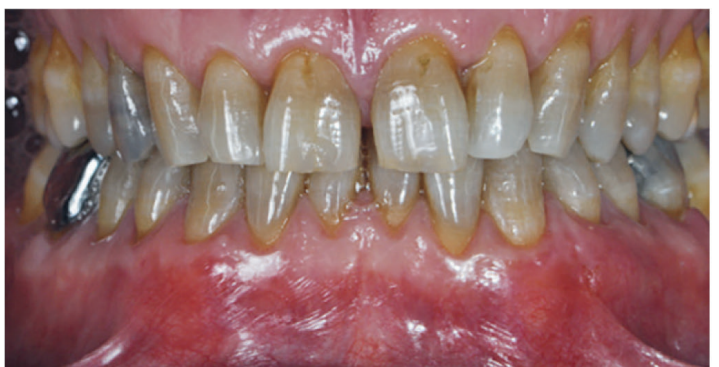

d

Figure 5

Treatment of gingival augmentation with the tunnel technique before orthodontic treatment to avoid an aggravation of the initial recessions on the maxilla and mandible (a) or just on the mandible (b).

an aggravation of the initial recession by vestibular orthodontic movement (Fig. 4 and 5). It will always be possible to perform periodontal surgery after orthodontic treatment, but gingival recoverage will have a less favorable prognosis. It is therefore necessary to minimize this risk of gingival recession. Even with such measures, patients with a fine biotype should be informed about the risks of gingival recession before orthodontic treatment begins.

\section{SURGICAL TUNNEL TECHNIQUE}

In the literature, the use of a subepithelial connective graft is the gold-standard treatment in terms of recoverage technique (80\%-85\% recoverage). The combination of this technique with a coronally displaced flap which covers the entire graft improves the coverage percentage $(90 \%-95 \%)^{5}$. The envelope technique initially described by Raetzke ${ }^{15}$ consists of the creation of a supraperiosteal "envelope" or "pocket" in which a subepithelial connective graft is slipped, without incision and without a flap for single recession coverage.

Then this procedure was specifically adapted by Allen with the tunnel technique for re-covering the root after multiple recessions. The unique feature of 
this procedure is that the interdental papillae remain intact. A connective tissue graft is placed in the tunnel. The flap does not completely cover the graft as long as it is large enough to ensure graft survival. The advantage of not completely covering the graft is the gain of keratinized tissue; however, the exposed tissue may become necrotic. The main advantage of this technique is the minimally invasive nature of the surgery, which results in negligible postoperative consequences at the recipient site. The major problem encountered by this technique is the limited mobility of the flap in the coronal direction. Azzi et $a l^{2}$ have therefore developed the tunnel technique for the treatment of multiple adjacent reces- sions. The use of a mucoperiostealmucosal flap makes it possible to obtain sufficient mobility to move the flap coronally without making an incision. This procedure allows optimal vascularization of the flap and graft, as well as rapid healing of the site (Fig. 6).

Recently, Zuhr et alls described a modified tunnel technique. This procedure optimizes the nutrition of the graft by creating a partial-thickness mucosal tunnel. A total-thickness flap is taken off only at the level of the papillae (Fig. 7).

Suspended sutures are employed to keep the flap in the coronal position (Fig. 8).

For recovery of a single gingival recession, the height of the recession, and the apically located keratinized
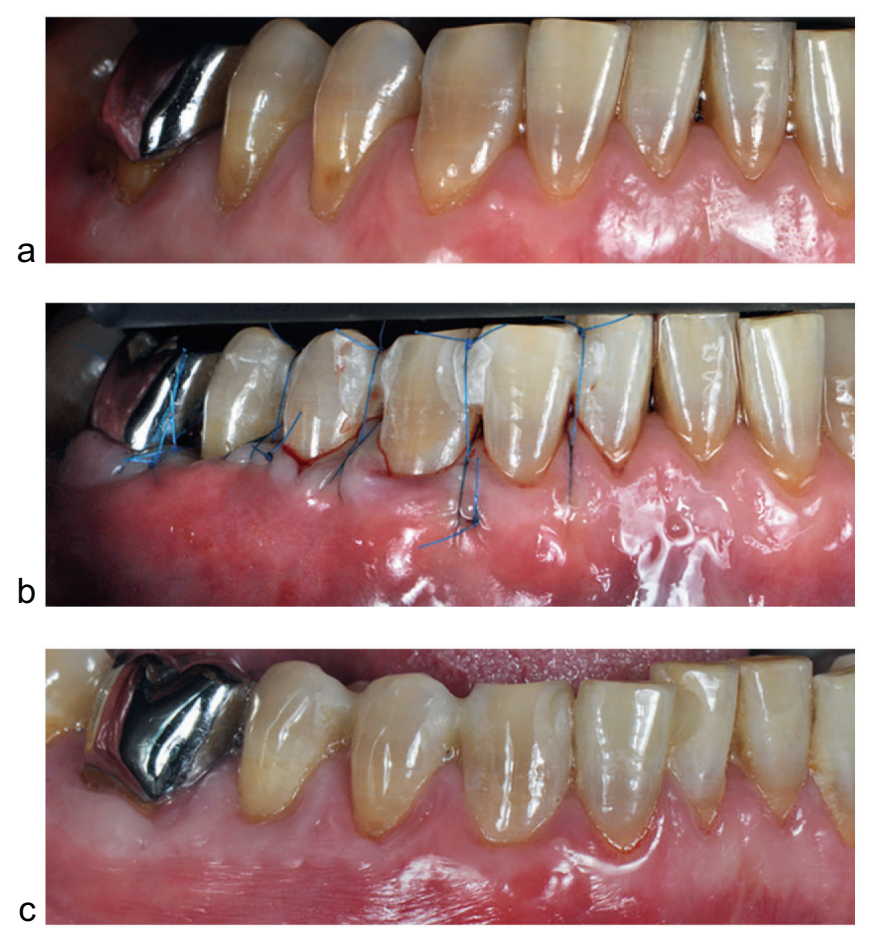

Figure 6

The tunnel technique has the benefits of optimal vascularization of the graft and flap. Note that this technique has quick results upon suture removal: (a) initial case, (b) end of surgery,

(c) removal of sutures after 10 days. 
gingiva, determines the choice of the procedure.

Zuhr and Hürzeler ${ }^{19}$ propose that when faced with a single recession $<3 \mathrm{~mm}$, repositioned flaps such as those in tunnel techniques can be used. In contrast, when the height of keratinized tissue apical to the recession is $<2 \mathrm{~mm}$, the tunnel technique will require the exposure of the graft. When the size of the recession is $>3 \mathrm{~mm}$, the tunnel technique cannot be used because of limited flap mobility in the coronal direction.

For the treatment of multiple gingival recessions, the modified tunnel technique can be used in all clinical situations. The exposure of the graft will depend on the height of the keratinized tissue apical to the recession. For a height $<2 \mathrm{~mm}$, portions of connective graft will be left exposed.
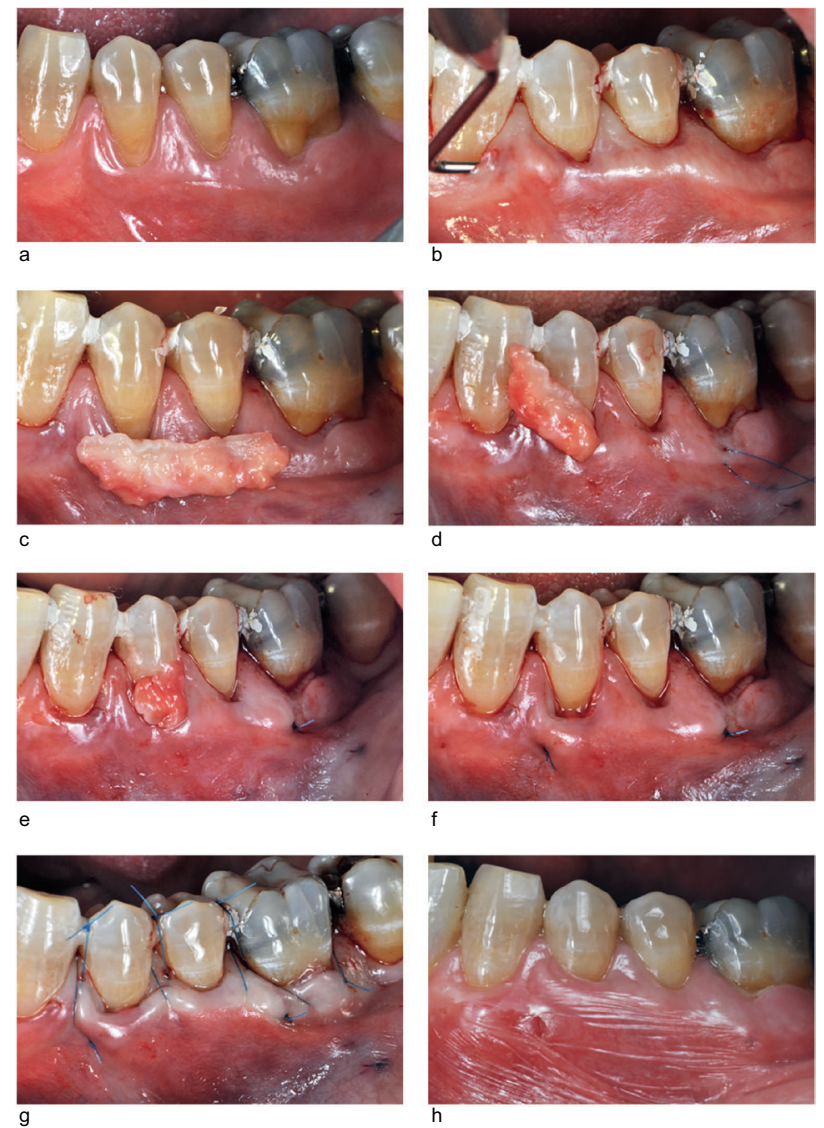

Figure 7

(a) initial case of class-I recession (b) Partial-thickness tunnel created. (c) Subepithelial connective graft. (d) Graft slipped into the tunnel. (e, f) Graft suture. (g) Making suspended

sutures for the coronal displacement of the flap. (h) 1-month postoperative outcome. 

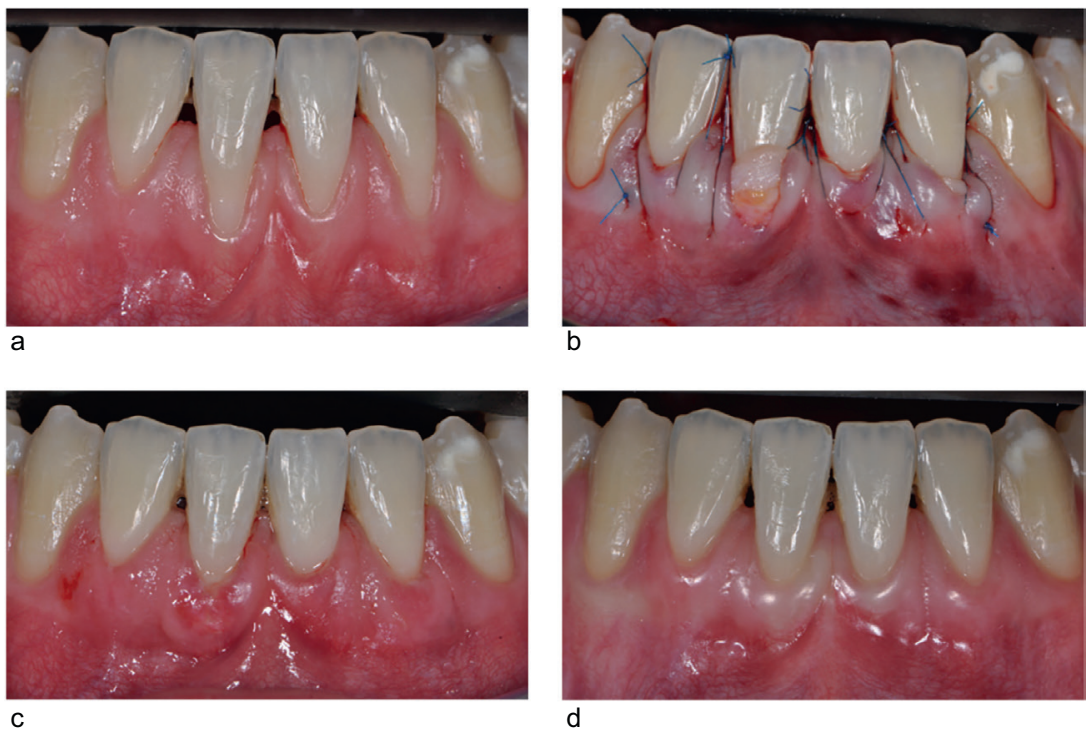

Figure 7

(a) Multiple recessions around the mandibular incisors after orthodontic treatment. (b) Tunnel technique with graft exposure at 32 and 41. (c) Removal of sutures after 10 days (d) results after 1 year. To note the increase in the height of the keratinized tissue.

\section{CONCLUSION}

Esthetic demands are perpetually progressing within our practices, and therefore the treatment of gingival recessions have become more frequent. The classification of recessions allows us to anticipate the prognosis of root-covering techniques. The modified tunnel technique is used to treat multiple recessions of adjacent teeth in patients with high esthetic expectations.
This new flap approach proved to be very effective in terms of root coverage and increased keratinized tissue. From an esthetic point of view, the perfect integration of the tissues, the absence of scarring, and the optimal vascular flow of this technique allows for a very satisfactory result.

Conflict of Interest: The author states that there is no conflict of interest.

\section{BIBLIOGRAPHY}

1. Allen A. Use of the supraperiosteal envelope in soft tissue grafting for root coverage. II. Clinical results. Int J Periodontics Restorative Dent 1994;14:302-315.

2. Azzi R, Etienne D, Takei $H$, Fenech P. Surgical thickening of the existing gingiva and reconstruction of interdental papillae around implant-supported restorations. Int J Periodontics Restorative Dent 2002;22:71-77. 
3. Bernimoulin JP, Luscher B, Mühlemann HR. Coronally repositioned periodontal flap. Clinical evaluation after one year. J Clin Periodontol 1975;2;1-13.

4. Cairo F, Nieri M, Cincinelli S, Mervelt J, Pagliaro U. The interproximal clinical attachment level to classify gin gival recessions and predict root coverage outcomes: an explorative and reliability study. J Clin Periodontol 2011;38:661-666.

5. Chambrone L, Pannuti CM, TuYK, Chambrone LA. Evidence-based periodontal plastic surgery. II. An individual data meta-analysis for evaluating factors in achieving complete root coverage. J Peridodontol 2012;83:477-490.

6. Coatoam G, Behrents R, Bissida N. The width of kerati nized gingiva during orthodontic treatment : its significance and impact on periodontal status. J Periodontol 1981;52:307-313.

7. Karring T, Ostergaard E, Löe H. Conservation of tissue specificity after hetero-topic transplantation of gingiva and alveolar mucosa. J Periodontal Res 1971;6;282-293.

8. Langer B, Langer L. Subepithelial connective tissue graft technique for root coverage. J Periodontol 1985;56;715-720.

9. Löst C. Depth of alveolar bone dehiscences in relation to gingival recessions. J Clin Periodontol 1984;11:583-589.

10. Merijohn GK. Management and prevention of gingival recession. Periodontol 2016; 71:228-242.

11. Miller PD Jr. A classification of marginal tissue recession. Int J Periodontics Restorative Dent 1985;5:8-13.

12. Nabers CL. Repositioning the attached gingiva. J Periodontol 1954;25;38-39.

13. Olsson $\mathrm{M}$, Lindhe J. Periodontal characteristics in individuals with varying form of the upper central incisors. J Clin Peridodontol 1991;18:78-82.

14. Olsson M, Lindhe J, Marinello C. On the relationship between crown forms and clinical features of the gingiva in adolescents. J Clin Periosdontology 1993;20:570-577.

15. Raetzke PB. Covering Localized areas of root exposure employing the " enveloppe " technique. J Periodontol 1985;56:397-402.

16. Steiner GG, Pearson JK, Ainamo J. Changes of the marginal periodontium as a result of labial tooth movement in monkeys. J Periodontol 1981;52:314-320.

17. Zucchelli G, Mazzotti C, Mounssif I, Mele M, Stefanini M, Montebugnoli L. A novel surgical-prosthetic approach for soft tissue dehiscence coverage around single implant. Clin Oral Implants Res 2013;24;957-962.

18. Zuhr O, Fickl S, Wachtel H, Bolz W, Hürzeler MB. Covering of gingival recessions with a modified microsurgical tunnel technique: case report. nt J Periodontics Restorative Dent 2007;27:456-463.

19. Zuhr O, Hürzeler M. Chirurgie plastique et esthétique en parodontologie et implantologie: une approche microchirurgicale. Quintessence International 2013. 